\title{
Effects of Omeprazole and Caffeine Alone and in Combination with Gentamicin and Ciprofloxacin Against Antibiotic Resistant Staphylococcus Aureus and Escherichia Coli Strains
}

\author{
Bibi Sedigheh Fazly Bazzaz ${ }^{1,2}$, Mahmoud Fakori3 ${ }^{3}$ Bahman Khameneh², \\ Hossein Hosseinzadeh ${ }^{4,5 *}$ \\ 1 Biotechnology Research Center, Institute of Pharmaceutical Technology, Mashhad University of Medical Sciences, Mashhad, Iran \\ ${ }^{2}$ Department of Pharmaceutical Control, School of Pharmacy, Mashhad University of Medical Sciences, Mashhad, Iran \\ ${ }^{3}$ School of Pharmacy, Mashhad University of Medical Sciences, Mashhad, Iran \\ ${ }^{4}$ Department of Pharmacodynamics and Toxicology, School of Pharmacy, Mashhad University of Medical Sciences, \\ Mashhad, Iran \\ ${ }^{5}$ Pharmaceutical Research Center, Pharmaceutical Technology Institute, Mashhad University of Medical Sciences, \\ Mashhad, Iran
}

\section{Key Words}

antimicrobial resistant, omeprazole, caffeine, Escherichia coli, Staphylococcus aureus, antibiotics

\begin{abstract}
Objective: Antibiotic resistance is a global health problem and threatens health of societies. These problems have led to a search for alternative approaches such as combination therapy. The aim of the present study was to investigate the effect of caffeine and omeprazole in combination with gentamicin or ciprofloxacin against standard and clinically resistant isolates of Staphylococcus aureus and Escherichia coli.
\end{abstract}

Methods: The minimum inhibitory concentration (MIC) and minimum bactericidal concentration (MBC) values of different agents against bacterial strains were determined. The interaction of non- antibiotic drugs with gentamicin and ciprofloxacin was studied in vitro using a checkerboard method and calculating fraction inhibitory concentration index (FICI). Verapamil as ef-

Received: Sep 19, 2018 Reviewed: Jan 29, 2019 Accepted: Feb 11, 2019

(c) This is an Open-Access article distributed under the terms of the Creative Common Attribution Non-Commercial License (http://creativecommons.org/licenses/by-nc/4.0/) which permits unrestricted noncommercial use, distribution, and reproduction in any medium, provided the original work is properly cited.

@ This paper meets the requirements of KS X ISO 9706, ISO 9706-1994 and ANSI/NISO Z39.48-1992 (Permanence of Paper). flux pump inhibitor was used to evaluate the possible mechanism of bacterial resistance to antibiotics.

Results: The MIC and MBC values of gentamicin against bacterial strains were in the range of 20-80 $\mu \mathrm{g} / \mathrm{ml}$ and 40-200 $\mu \mathrm{g} / \mathrm{ml}$, respectively. Caffeine and omeprazole had no intrinsic inhibitory activity against tested microorganisms. However, upon combination of caffeine with antibiotics, the synergistic effects were observed. Verapamil was able to reduce the MIC values of gentamicin ( 4 folds) only in some bacterial strains.

Conclusion: These findings indicated that caffeine was effective in removing bacterial infection caused by $S$. aureus and E. coli. The relevant mechanisms of antibiotic resistance were not related to the drug efflux.

\section{Introduction}

Antibiotic resistance has been considered as serious problem in treating bacterial infections $[1,2]$. Serious consequences have been reported for infection by resistant pathogens such as higher doses of antibiotics administration, prolonged hospitalizations and also associated with increased morbidity and mortality [3]. 
Gentamicin and ciprofloxacin are potent antibiotic and used for the treatment of both type of bacteria $[4,5]$. Despite the wide range of application, the antibiotic shows some drawbacks which are limited the routine administration like increased resistance to it [6].

To date, different approaches have been employed to overcome bacterial resistances $[7,8]$. The combination therapy of antibiotics is useful and desirable ones and shows certain advantages like increasing the antibiotic activity, reducing the risk of resistance to antibiotics [9]. Repurposing and revival of non-antibiotic drugs which having potential antibacterial activity would be desirable for reducing the risk of increasing resistance and also toxicity.

Methylxanthines are potent bronchodilator agents and widely used as acute asthma treatment. They show wide range of pharmacological activities such as antimicrobial activities against some pathogens [10-13]. For instance, aminophylline and caffeine increased the antibiotic activities of carbenicillin, ceftizoxime and gentamicin against Staphylococcus aureus and Pseudomonas aeruginosa. Previously, it was confirmed that caffeine was able to decrease the MIC values of gentamicin against $S$. $a u$ reus and $P$. aeruginosa $[14,15]$. Additionally, the antimicrobial properties of caffeine against Candida albicans were reported $[16,17]$. Different mechanisms have been mentioned about antibacterial activity of caffeine such as inhibiting incorporation of adenine and thymidine in the synthesis of DNA via inhibition of thymidine kinase and also inhibiting the synthesis of DNA $[18,19]$.

The extrusion of antibiotics via efflux pump is primary mechanism by which bacteria can resist the action of antibiotics. These pumps are complexes within the bacterial cell envelope and are mainly used to export toxic substances such as antibiotics and found in wide range of multi- drug resistant nosocomial pathogens [20]. Therefore, targeting bacterial efflux pumps could effectively re-sensitize resistant bacterial strains to broad spectrum of antibiotics. Omeprazole as proton pump inhibitors (PIPs) and a class of efflux pump inhibitor (EPIs) is used to overcome antibiotic resistance in $S$. aureus [21, 22].

So that, the aim of the present study was to evaluate the antibacterial activities of gentamicin and ciprofloxacin in combination with omeprazole and caffeine against resistant human pathogens.

\section{Materials and methods}

\subsection{Materials}

Caffeine, omeprazole, ciprofloxacin and gentamicin were obtained from Darou Pakhsh Pharmaceutical Company (Tehran, Iran). Muller Hinton broth (MHB) and Tryptone Soya Agar plates (TSA) were purchased from Hi media (India). TTC (triphenyl tetrazolium chloride) was purchased from Merck (Germany). All of the original samples were used on arrival. Water used was double-distilled water.

\subsection{Bacterial strains}

The antibacterial activity was evaluated against four clinically resistant Gram positive bacteria: Staphylococcus au- reus (S. aureus) and two isolated of Gram negative bacteria: Escherichia coli (E. coli) which were received from the Clinical Microbiology Laboratory, University Hospital of Imam Reza, in Mashhad, Iran, as multidrug resistant isolates.

The standard strain of $S$. aureus ATCC43300 which is MRSA (methicillin resistance $S$. aureus) was used as control strain. Bacterial strains were maintained by subculture on TSA to their growth at $37^{\circ} \mathrm{C}$ for $24 \mathrm{~h}$.

\subsection{Determination of minimum inhibitory concentration (MIC) and minimum bactericidal concentration (MBC) values}

The MIC values of gentamicin, omeprazole and caffeine against pathogens was determined as previously described [23]. Briefly, approximately $10^{6} \mathrm{CFU} / \mathrm{mL}$ cells from overnight bacterial cultures were used as inoculum. Serial dilutions of each compound were prepared in MHB in 96- well microtiter plates. Then, the inoculum was added to each well to obtain $10^{5} \mathrm{CFU} / \mathrm{mL}$ at final bacterial concentration. The inoculated microplates were incubated at $37^{\circ} \mathrm{C}$ for $24 \mathrm{~h}$ under aerobic condition. MIC was determined by adding $20 \mu \mathrm{L}$ of $5 \mathrm{mg} / \mathrm{mL}$ of TTC to each well plus incubating at $37^{\circ} \mathrm{C}$ for $30 \mathrm{~min}$.

For MBC determination, an aliquot of $10 \mu \mathrm{L}$ from all wells and tubes without growth was seeded in TSA. The plates were then incubated for overnight at $37^{\circ} \mathrm{C}$. As definition, $\mathrm{MBC}$ is the lowest concentration of antimicrobial agent that kills $>99.9 \%$ of bacteria.

\subsection{Synergism testing}

To evaluate the synergistic effect of the combination of antibiotics, gentamicin and ciprofloxacin, and non-antibiotic drugs, caffeine and omeprazole, the checkerboard method was used [8]. The MIC was assayed as mentioned above and finally to assess the synergistic activity the fractional inhibitory concentration index [24] value was used.

FICI(fractional inhibitory concentration index) of the antibacterial agent combination was FIC (drug A) + FIC (drug B), and also the FIC is equal to (MIC of drug A in combination) / (MIC of drug A alone). The combination effects were analyzed according to the following criteria; $<0.5$ denoting synergy; 0.5-0.75 denoting partial synergy; 0.76-1 denoting an additive effect; 1-4 denoting indifference; and $>4$ denoting antagonism [25].

\subsection{Statistical analysis}

All experiments were performed three times. Results were presented as mean $\pm \mathrm{SD}$.

\section{Results}

\subsection{Determination of MIC and MBC values}

The MIC and MBC values of gentamicin, omeprazole and caffeine for each bacterial strains were illustrated in Table 1. As seen, these values for caffeine and omeprazole were more than $200 \mu \mathrm{g} / \mathrm{mL}$. 
Table 1 Minimum inhibitory concentration (MIC) and minimum bactericidal concentration (MBC) values of gentamicin against Staphylococcus aureus and Escherichia coli strains.

\begin{tabular}{|c|c|c|c|}
\hline \multirow[b]{3}{*}{ Staphylococcus aureus } & \multirow{3}{*}{$\begin{array}{c}\text { Strain } \\
1\end{array}$} & \multicolumn{2}{|c|}{ Gentamicin } \\
\hline & & \multicolumn{2}{|c|}{$(\mu \mathrm{g} / \mathrm{ml})$} \\
\hline & & $>80$ & $>80$ \\
\hline S. aureus & 2 & 20 & 40 \\
\hline S. aureus & 3 & $>80$ & $>80$ \\
\hline S. aureus & 4 & $>80$ & $>80$ \\
\hline $\begin{array}{c}\text { S. aureus } \\
\text { (ATCC 43300) }\end{array}$ & 5 & 50 & 200 \\
\hline Escherichia coli & 1 & 100 & 200 \\
\hline E. coli & 2 & 50 & 200 \\
\hline
\end{tabular}

Table 2 Results of the combination of gentamicin and caffeine against Staphylococcus aureus and Escherichia coli.

\begin{tabular}{|c|c|c|c|c|c|c|c|}
\hline \multirow{2}{*}{$\begin{array}{c}\text { Bacterial } \\
\text { strains }\end{array}$} & \multirow{2}{*}{ Strain } & \multirow{2}{*}{ Agent } & \multicolumn{2}{|c|}{ MIC $(\mu \mathrm{g} / \mathrm{ml})$} & \multirow{2}{*}{ FIC } & \multirow{2}{*}{ FICI } & \multirow{2}{*}{ Outcome } \\
\hline & & & Alone & $\begin{array}{l}\text { gentamicin } \\
+ \text { caffeine }\end{array}$ & & & \\
\hline \multirow{2}{*}{$\begin{array}{c}\text { Staphylococcus } \\
\text { aureus }\end{array}$} & \multirow[t]{2}{*}{1} & gentamicin & 100 & 100 & 1 & \multirow[t]{2}{*}{2} & \multirow[t]{2}{*}{ Indifference } \\
\hline & & caffeine & 200 & 200 & 1 & & \\
\hline \multirow[t]{2}{*}{ S. aureus } & \multirow[t]{2}{*}{2} & gentamicin & 12.5 & 6.25 & 0.5 & \multirow[t]{2}{*}{0.75} & Partial \\
\hline & & caffeine & 200 & 50 & 0.25 & & synergy \\
\hline \multirow[t]{2}{*}{ S. aureus } & \multirow[t]{2}{*}{3} & gentamicin & 100 & 100 & 1 & \multirow[t]{2}{*}{2} & \multirow[t]{2}{*}{ Indifference } \\
\hline & & caffeine & 200 & 200 & 1 & & \\
\hline \multirow[t]{2}{*}{ S. aureus } & \multirow[t]{2}{*}{4} & gentamicin & 100 & 100 & 1 & \multirow[t]{2}{*}{2} & \multirow[t]{2}{*}{ Indifference } \\
\hline & & caffeine & 200 & 200 & 1 & & \\
\hline \multirow{2}{*}{$\begin{array}{c}\text { S. aureus } \\
\text { (ATCC 43300) }\end{array}$} & \multirow{2}{*}{5} & gentamicin & 50 & 25 & 0.5 & \multirow{2}{*}{1.5} & \multirow[t]{2}{*}{ Indifference } \\
\hline & & caffeine & 200 & 200 & 1 & & \\
\hline \multirow[t]{2}{*}{ Escherichia coli } & \multirow{2}{*}{1} & gentamicin & 100 & 50 & 0.5 & \multirow{2}{*}{1} & \multirow[t]{2}{*}{ Partial } \\
\hline & & caffeine & 200 & 50 & 0.25 & & \\
\hline \multirow[t]{2}{*}{ E. coli } & \multirow[t]{2}{*}{2} & gentamicin & 50 & 50 & 1 & \multirow[t]{2}{*}{2} & \multirow[t]{2}{*}{ Indifference } \\
\hline & & caffeine & 200 & 200 & 1 & & \\
\hline
\end{tabular}

\subsection{Synergism of gentamicin and non-antibi- otic drugs}

The combined effects of gentamicin and non-antibiotic drugs were shown in Tables 2 and 3.

Based on these results, for two clinical isolates the partial synergistic effect was observed. The FICI values were 0.75 for S. aureus, strain 2, and 1 for E. coli, strain 1, respectively. As seen, The FICI values for all microorganisms were 2 and the "indifference" outcome reflected in the table. The results of this part of study indicated that combination of gentamicin with omeprazole was not effective and omeprazole was ineffective against bacterial strains both administrated alone or in combination with antibiotic. The results of combination of ciprofloxacin with caffeine 
Table 3 Results of the combination of gentamicin and omeprazole against Staphylococcus aureus and Escherichia coli.

\begin{tabular}{|c|c|c|c|c|c|c|c|}
\hline \multirow{2}{*}{$\begin{array}{c}\text { Bacterial } \\
\text { strains }\end{array}$} & \multirow{2}{*}{ Strain } & \multirow{2}{*}{ Agent } & \multicolumn{2}{|c|}{ MIC $(\mu \mathrm{g} / \mathrm{ml})$} & \multirow{2}{*}{ FIC } & \multirow{2}{*}{ FICI } & \multirow{2}{*}{ Outcome } \\
\hline & & & & gentamicin & & & \\
\hline \multirow{2}{*}{ Staphylococcus } & \multirow{3}{*}{1} & & & + & & \multirow{3}{*}{2} & \multirow{3}{*}{ Indifference } \\
\hline & & gentamicin & 100 & 100 & 1 & & \\
\hline aureus & & omeprazole & 200 & 200 & 1 & & \\
\hline \multirow{2}{*}{ S. aureus } & \multirow[b]{2}{*}{2} & gentamicin & 12.5 & 12.5 & 1 & \multirow[b]{2}{*}{2} & \multirow{2}{*}{ Indifference } \\
\hline & & omeprazole & 200 & 200 & 1 & & \\
\hline \multirow{3}{*}{ S. aureus } & \multirow{3}{*}{3} & gentamicin & 100 & 100 & 1 & \multirow{3}{*}{2} & \multirow{3}{*}{ Indifference } \\
\hline & & & & & & & \\
\hline & & omeprazole & 200 & 200 & 1 & & \\
\hline \multirow{3}{*}{ S. aureus } & \multirow{3}{*}{4} & gentamicin & 100 & 100 & 1 & \multirow{3}{*}{2} & \multirow{3}{*}{ Indifference } \\
\hline & & & & & & & \\
\hline & & omeprazole & 200 & 200 & 1 & & \\
\hline \multirow{2}{*}{$\begin{array}{c}\text { S. aureus } \\
\text { (ATCC 43300) }\end{array}$} & \multirow{2}{*}{5} & gentamicin & 50 & 50 & 1 & \multirow{2}{*}{1.5} & \multirow{2}{*}{ Indifference } \\
\hline & & omeprazole & 200 & 200 & 1 & & \\
\hline \multirow[t]{2}{*}{ Escherichia } & \multirow{3}{*}{1} & gentamicin & 100 & 100 & 0.5 & \multirow{3}{*}{2} & \multirow{3}{*}{ Indifference } \\
\hline & & & & & & & \\
\hline coli & & omeprazole & 200 & 200 & 1 & & \\
\hline \multirow{3}{*}{ E. coli } & \multirow{3}{*}{2} & gentamicin & 50 & 50 & 1 & \multirow{3}{*}{2} & \multirow{3}{*}{ Indifference } \\
\hline & & & & & & & \\
\hline & & omeprazole & 200 & 200 & 1 & & \\
\hline
\end{tabular}

and omeprazole showed that enhanced antibacterial activities were not observed by combination therapy (data not shown).

In order to investigate the role of efflux pump in bacterial resistance; verapamil, as a potent efflux pump inhibitor, was used in combination with gentamicin in some of the clinical isolates. The results showed that in presence of verapamil, the synergistic effects were observed, (FICI = 0.37 ), and the MIC values of gentamicin were reduced 4 folds only in specific bacterial strains; mainly $S$. aureus.

\section{Discussion}

Clinical isolates of bacteria are mainly causes of nosocomial infections and currently considered as clinical and public health problem. These problems have led to develop alternative approaches such as combination therapy. By this approach therapeutic outcomes were enhanced and also the adverse effects of antibiotic drugs were also reduced. Therefore, in the present study the combination of antibiotics, gentamicin and ciprofloxacin with non-antibiotic drugs, caffeine and omeprazole, was evaluated.

The MIC and MBC values of gentamicin against bacterial strains (Table 1) indicated that isolated strains were resistant to antimicrobial agent and higher concentration of antibiotics is needed to remove bacterial infections. So that, combination of non-antibiotic drugs with antibiotics was used as an approach to enhance the antibacterial activity and also reduce the concentration of the antibiotic.

To date, some studies indicated the antibacterial activity of methylxanthines $[10,15]$. In the present study, the combinatorial effect of caffeine and gentamicin was investigated (Table 2). These data indicated that the synergistic effects were only observed in some of the clinical isolates. These results were in line with previous published data which showed that methylxanthines did not show promising results when combined with antibiotics. However, it was shown that caffeine was more effective in Gram-positive bacteria in comparison with Gram-negative ones [1]. In the present study, this combination showed a synergistic effect against both types of Gram-negative and -positive bacteria and which confirmed that type of species plays an important role in evaluating the combination effects. Additionally, it was shown that combination of cell walltargeting antibiotics such as penicillin and cephalosporin with caffeine yield synergistic effects. These observations might be due to the antibiotics facilitated the diffusion of caffeine into microorganisms and therefore better interaction with DNA [15]. However, both gentamicin and caffeine affected on DNA and consequently the antibiotic activity did not alter remarkably.

Efflux-mediated resistance is a well-known mechanism in bacterial resistance and therefore finding a solution to remove or bypass efflux systems is attractive. Efflux pump inhibitors (EPIs) drugs have been shown promising results since a single EPI that is active against efflux pumps of bacteria and can be used as combination therapy. Several of them are non-antibiotic drugs and have demonstrated efflux pump inhibitory properties on NorA and other resistance pumps (MDR pumps) of Gram-positive 
organisms. Omeprazole, as an EPI, and some analogs of it have been used to evaluate the antibacterial activity. The results indicated that some analogs were able to restore the bactericidal activity of norfloxacin [22]. Additionally, omeprazole which is usually used in treatment of Helicobacter pylori infection, can reduce the MICs of the antibiotics in MDR strains of $H$. pylori [26]. The results of present study were in contrast with Multidrug these findings and the antibacterial activity of antibiotics were not changed by combination with omeprazole (Table 3 ). Based on these observations, it can be assumed that the efflux pump was not active in tested bacteria. In order to deep investigate, verapamil as potent EPI was combined with gentamicin and the synergistic effects were tested [27].

The MIC values of gentamicin were reduced in only some of the bacterial strains. So that, it can be assumed that the antibiotic resistance of the strains which were used in the present study might be related to the other resistance mechanisms and the mechanism of drug efflux was not mainly effective.

\section{Conclusion}

Present findings indicated that caffeine, a bronchodilator agent, was able to reduce the drug resistance of clinically isolates of $S$. aureus and E. coli, but omeprazole as a EPIs was not effective in removing bacterial infection. The relevant mechanisms of antibiotic resistance were not related to the drug efflux in these bacteria.

\section{Conflict of interest}

All authors declared that there is no conflict of interest.

\section{Acknowledgment}

The authors are thankful to the Vice Chancellor of Research, Mashhad University of Medical Sciences for financial supports. The results described in this paper are part of a Pharm. D. thesis.

\section{References}

1. Khameneh B, Diab R, Ghazvini K, Fazly Bazzaz BS. Breakthroughs in bacterial resistance mechanisms and the potential ways to combat them. Microb Pathog. 2016;95:32-42.

2. Khademi F, Poursina F, Hosseini E, Akbari M, Safaei HG. Helicobacter pylori in Iran: A systematic review on the antibiotic resistance. Iran J Basic Med Sci. 2015;18:2-7. Epub 2015/03/27.

3. Fazly Bazzaz BS, Khameneh B, Zahedian Ostad MR, Hosseinzadeh $\mathrm{H}$. In vitro evaluation of antibacterial activity of verbascoside, lemon verbena extract and caffeine in combination with gentamicin against drug-resistant Staphylococcus aureus and Escherichia coli clinical isolates. Avicenna J Phytomed. 2018;8:246-53.

4. Pantosti A, Sanchini A, Monaco M. Mechanisms of antibiotic resistance in Staphylococcus aureus. Future Microbiol. 2007;2:323-34.

5. Corvec S, Tafin UF, Betrisey B, Borens O, Trampuz A. Activities of fosfomycin, tigecycline, colistin, and gentamicin against extended-spectrum-lactamase-producing Escherichia coli in a foreign-body infection model. Antimicrob Agents Chemother. 2013;57:1421-7.

6. Fazly Bazzaz BS, Sarabandi S, Khameneh B, Hosseinzadeh H. Effect of Catechins, Green tea Extract and Methylxanthines in Combination with Gentamicin Against Staphylococcus aureus and Pseudomonas aeruginosa: Combination therapy against resistant bacteria. J Pharmacopuncture. 2016;19:312-8.

7. Forouzanfar F, Bazzaz BS, Hosseinzadeh H. Black cumin (Nigella sativa) and its constituent (thymoquinone): a review on antimicrobial effects. Iran J Basic Med Sci. 2014;17:929- 38. Epub 2015/04/11.

8. Khameneh B, Fazly Bazzaz BS, Amani A, Rostami J, Vahdati-Mashhadian N. Combination of anti-tuberculosis drugs with vitamin C or NAC against different Staphylococcus aureus and Mycobacterium tuberculosis strains. Microb Pathog. 2016;93:83-7.

9. Hagihara M, Crandon JL, Nicolau DP. The efficacy and safety of antibiotic combination therapy for infections caused by Gram-positive and Gram-negative organisms. Expert Opin Drug Saf. 2012;11:221-33. Epub 2011/11/15.

10. Elgaher WA, Hayallah AM, Salem OIA, Abdel Alim AAM. Synthesis, anti-vbronchoconstrictive, and antibacterial activities of some new 8-substituted-1,3-dimethylxanthine derivatives. Bulletin of Pharmaceutical Sciences. 2009;32:153-87.

11. Hayallah AM, Elgaher WA, Salem OI, Abdel Alim AAM. Design and synthesis of some new theophylline derivatives with bronchodilator and antibacterial activities. Archives of Pharmacal Research. 2011;34:3-21.

12. Hosseinzadeh $\mathrm{H}$, Bazzaz F, Ahmadzadeh S. In vitro evaluation of methylxanthines and some antifungal drugs: interaction against Candida albicans. Pharmaceutical and Pharmacological Letters. 2000;11:34-6.

13. Hosseinzadeh H, Mehrabi M. Effect of R-Phenylpropyladenosine and methylxathines on memory and learning peformance in goldfish. Pharmacologyonline 
2009;2:686-689.

14. Bazzaz BS, Lavaei S, Hosseinzadeh H. Interaction of methylxanthines and gentamicin against Staphylococcus aureus and Pseudomonas aeruginosa: role of phosphodiesterase inhibition. Acta Microbiol Immunol Hung. 2012;59:13-20.

15. Hosseinzadeh H, Bazzaz BSF, Sadati MM. In vitro evaluation of methylxanthines and some antibiotics: Interaction against Staphylococcus aureus and Pseudomonas aeruginosa. Iranian Biomedical Journal. 2006;10:163-7. Gyawali R, Adkins A, C. Minor R, Ibrahim SA. Be-

16. havior and changes in cell morphology of Escherichia coli $\mathrm{O} 157: \mathrm{H} 7$ in liquid medium and skim milk in the presence of caffeine. CYTA - Journal of Food. 2014;12(3):235-41.

Kim YW, Chun HJ, Kim IW, Liu HB, Ahn WS. Antimicro-

17. bial and antifungal effects of green tea extracts against microorganisms causing vaginitis. Food Science and Biotechnology. 2013;22:713-9.

Labbe RG, Nolan LL. Inhibition of macromolecular

18. synthesis by caffeine in Clostridium perfringens. Can J Microbiol. 1987;33:589-92.

Sandlie I, Solberg K, Kleppe K. The effect of caffeine on

19. cell growth and metabolism of thymidine in Escherichia coli. Mutat Res. 1980;73:29-41.

Fleeman RM, Debevec G, Antonen K, Adams JL, Santos

20. RG, Welmaker GS, et al. Identification of a novel polyamine scaffold with potent efflux pump inhibition activity toward multi-drug resistant bacterial pathogens. Front Microbiol. 2018;9:1301. Epub 2018/07/03.

Aeschlimann JR, Dresser LD, Kaatz GW, Rybak MJ. Ef-

21. fects of NorA inhibitors on in vitro antibacterial activities and postantibiotic effects of levofloxacin, ciprofloxacin, and norfloxacin in genetically related strains of Staphylococcus aureus. Antimicrob Agents Chemother. 1999;43:335- 40. Epub 1999/01/30.

Vidaillac C, Guillon J, Arpin C, Forfar-Bares I, Ba BB,

22. Grellet J, et al. Synthesis of omeprazole analogues and evaluation of these as potential inhibitors of the multidrug efflux pump NorA of Staphylococcus aureus. Antimicrob Agents Chemother. 2007;51:831-8. Epub 2006/11/15.

Fazly Bazzaz BS, Khameneh B, Namazi N, Iranshahi M,

23. Davoodi D, Golmohammadzadeh S. Solid lipid nanoparticles carrying Eugenia caryophyllata essential oil: the novel nanoparticulate systems with broad-spectrum antimicrobial activity. Lett Appl Microbiol. 2018;66:506-13.

Pacifici GM. Clinical pharmacokinetics of penicillins,

24. cephalosporins and aminoglycosides in the neonate: $\mathrm{A}$ review. Pharmaceuticals. 2010;3:2568-91.

Khameneh B, Iranshahy M, Ghandadi M, Ghoochi

25. Atashbeyk D, Fazly Bazzaz BS, Iranshahi M. Investigation of the antibacterial activity and efflux pump inhibitory effect of co- loaded piperine and gentamicin nanoliposomes in methicillin-resistant Staphylococcus aureus. Drug Dev Ind Pharm. 2015;41:989-94.

26. Zhang Z, Liu ZQ, Zheng PY, Tang FA, Yang PC. Influence of efflux pump inhibitors on the multidrug resistance of Helicobacter pylori. World J Gastroenterol.
2010;16:1279-84. Epub 2010/03/12.

27. Cabral V, Luo X, Junqueira E, Costa SS, Mulhovo S, Duarte A, et al. Enhancing activity of antibiotics against Staphylococcus aureus: Zanthoxylum capense constituents and derivatives. Phytomedicine. 2015;22:469-76. 